\title{
ICE-BRINE DENDRITIC AGGREGATE FORMED ON FREEZING OF AQUEOUS SOLUTIONS
}

\author{
By P. K. Rohatgi \\ (The International Nickel Company, Inc., Paul D. Merica Research Laboratory, Sterling \\ Forest, Suffern, New York, U.S.A.) \\ and C. M. Adams, Jr. \\ (Department of Metallurgy, Massachusetts Institute of Technology, Cambridge, \\ Massachusetts, U.S.A.)
}

Anstract. Dendritic aggregates of ice and brine formed upon freezing of aqueous solutions have been studied. Chlorides of sodium, potassium, lithium and hydrogen were used as solutes; structures produced on freezing of binary, ternary and quaternary solutions were examined. Effects of freezing rate, solute concentration, solute diffusivity, mixing of solutions and magnetic fields are reported.

The spacing between ice platelets or dendrites was found experimentally to be proportional to the square root of the freezing time when the freezing rate was constant from beginning to end of solidification. During unidirectional freezing from a constant temperature chill, the solution at each location is subjected to a spectrum of freezing rates; dendrite spacing increases linearly with distance from the chill surface and it is inversely proportional to the square root of the maximum freezing rate.

In binary solutions dendrite spacing increases linearly with solute concentration; above a critical solute concentration ice platelets develop side branches. Application of an external magnetic field has an effect similar to increasing concentration. At a given solute concentration, spacing between ice dendrites increases linearly with solute diffusivity.

In ternary and quaternary solutions dendrite spacing is a function of the concentrations and diffusivities of each of the constituent solutes.

RÉsumé. Aggregat dendritique de glace et de saumure formé par le gel de solutions aqueuses. Des aggregats dendritiques de glace et de saumure, formés lors du gel de solutions aqueuses, ont été étudiés. Des chlorures de sodium, potassium, lithium et hydrogène ont été utilisés comme sels; les structures, produites par le gel de solutions binaires, tertiaires et quaternaires, ont été examinées. Les effets de la vitesse de congélation, de la concentration de la solution, de la vitesse de diffusion du sel, du mélange des solutions et des champs magnétiques,
sont donnés.

L'espacement entre les plaquettes de glace ou les dendrites s'est révélé expérimentalement être proportionnel à la racine carrée du temps de congélation lorsque la vitesse de congélation était constante du début à la fin de la solidification. Pendant une congélation unidirectionnelle par un abaissement de température constant, la solution en chaque point est sujette à un spectre de vitesses de congélation; l'espacement entre les dendrites augmente linéairement avec la distance de la surface de refroidissement et il est inversement proportionnel à la racine carrée du maximum de la vitesse de congélation.

Dans les solutions binaires, l'espacement entre les dendrites augmente linéairement avec la concentration; au-dessus d'une concentration critique, les plaquettes de glace développent des arborescences. L'application d'un champ magnétique externe a le même effet que l'augmentation de concentration. Pour une concentration donnée, l'espacement entre les dendrites de glace augmente linéairement avec la vitesse de diffusion de la
solution.

Dans les solutions ternaires et quaternaires, l'espacement est une fonction des concentrations et des vitesses de diffusion de chacun des sels.

Zusammenfassung. Dendritische Eis-Sole-Aggregate, entstehend beim Gefrieren wässriger Lösungen. Dendritische Aggregate von Eis und Salzwasser, die beim Gefrieren von wässrigen Lösungen entstehen, wurden studiert. Als Lösungen wurden Chloride von Sodium, Potassium, Lithium und Wasserstoff benutzt. Froststrukturen von zweifachen, dreifachen und vierfachen Lösungen wurden untersucht. Es wird über den Einfluss der Gefriergeschwindigkeit, der Lösungskonzentration, des Diffusionsvermögens der Lösung, der Mischung von Lösungen und der Magnetfelder berichtet.

Der Zwischenraum zwischen Eisplättchen oder Dendriten wurde experimentell als proportional zur Wurzel aus der Gefrierzeit gefunden, wenn die Gefriergeschwindigkeit vom Beginn bis zum Abschluss der Verfestigung konstant war. Bei einseitig gerichtetem Gefrieren von einer konstanten Kältequelle aus ist die Lösung an jeder Stelle einem Spektrum von Gefriergeschwindigkeiten ausgesetzt; die Dendritenabstände wachsen linear mit dem Abstand von der Kältequelle und sind umgekehrt proportional zur Wurzel aus der maximalen Gefriergeschwindigkeit.

In zweifachen Lösungen wachsen die Dendritenabstände linear mit der Lösungskonzentration; über einer kritischen Lösungskonzentration entwickeln die Eisplättchen Seitenarme. Ein äusseres Magnetfeld wirkt sich ähnlich aus wie eine Steigerung der Konzentration. Bei fester Konzentration wächst der Dendritenabstand linear mit dem Diffusionsvermögen der Lösung.

In drei- und vierfachen Lösungen ist der Dendritenabstand eine Funktion der Konzentration und des Diffusionsvermögens jeder der beteiligten Lösungen. 


\section{INTRODUGTION}

Structures of ice produced on freezing of aqueous solutions are extremely important in understanding the glacial phenomenon. In addition, usefulness of sea ice as a structural material depends to a great extent on its salinity (Kingery, I960) and distribution of brine in the solid aggregate. Aqueous solutions of most ionic salts freeze by separation of practically pure ice crystals from the liquid phase; with very few exceptions, there is virtually no solid solubility of ionic salts in ice. The morphology of freezing ice crystals is of great importance in attempting to achieve separation from the brine in production of fresh water.

As an ice crystal grows there is rejection of solute from the moving interface into the liquid. Since the rejected solute moves primarily by diffusion, concentration gradients are established in the liquid. The highest solute concentrations are found in the liquid immediately adjacent to liquid-solid interfaces and lowest concentrations at locations farthest from these interfaces. The velocity with which a solid-liquid interface can grow locally is determined by the speed with which the solute can diffuse away from the solid-liquid interface. Since liquid diffusivities are quite low, the growth velocity is correspondingly low. However, the overall rate of liquid to solid conversion is dictated by the rate of heat extraction. To transform at the rate required by heat flow, ice crystals grow as arrays of parallel plates or dendrites. Solidification progresses by simultaneous longitudinal and transverse growth of ice plates. During growth most of the solute is rejected in the interdendritic liquid between neighboring plates where it is deposited as brine layers towards the end of the solidification cycle. The spacing between ice plates or brine layers governs the properties of the solid aggregate. Weeks and Assur (I963) have shown that vertical variation in the strength of sea ice is due to a change in the distribution of solute pockets. Bennington ( 1963 ) has discussed the variation in salinity of Arctic ice with depth and its effect on properties.

Most of the work done on the formation of ice has been either on pure water or dilute solutions (Dorsey, 1948; Himes and others, r959; Harrison and Tiller, 1963; French, unpublished). The present investigation was concerned with factors which affect spacing between ice dendrites in solutions up to fairly high concentration levels. The effects of freezing rates, solute concentration, solute diffusivity, the presence of more than one solute in a solution and external magnetic fields were investigated.

\section{THEORY}

\section{Mass transport}

An analysis of mass-transport events in the interdendritic liquid between two growing plates (Figs. I and 2) provides a basis for quantitative interpretation of experimentally observed dendritic structures. The main purpose of the analytical treatment of interdendritic liquid diffusion is to relate the dendrite spacing and the maximum concentration differences in this region to solidification variables. Most analyses on re-distribution of solute have been

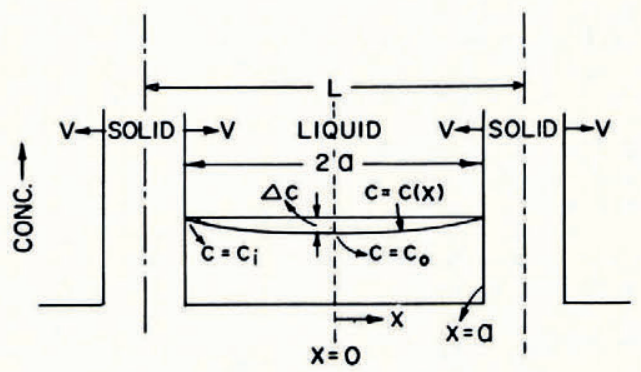

Fig. 1. Schematic representation of solute-concentration profile in the interdendritic liquid between two ice plates 


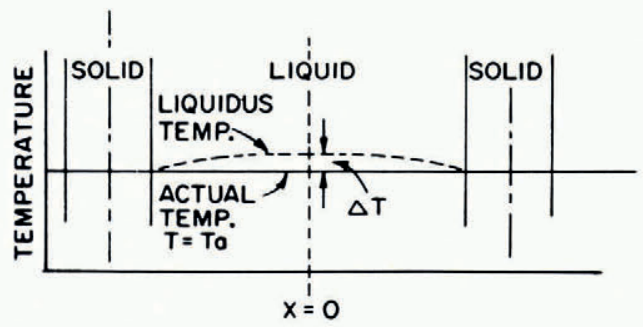

Fig. 2. Actual-temperature and liquidus-temperature distributions in the interdendritic liquid

for a case where the solute is being rejected into a large volume of liquid ahead of a plane interface (Tiller and others, I953). In the present situation, solute is being rejected into both sides of a liquid region bounded by parallel planes; in addition, these planes are simultaneously moving towards each other.

The solute rejected at the interface $(X=a)$ moves towards the center of the interdendritic liquid region $(X=0)$, producing a concentration gradient in the liquid (Fig. I). The concentration difference $(\Delta C)$ between the center $\left(C=C_{0}\right)$ and the bounding surface $\left(C=C_{i}\right)$ is directly proportional to supercooling, $\Delta T$, prevailing in the center of the liquid region (Fig. 2). For binary solutions, solute concentration should conform to Fick's second law:

$$
\frac{\partial C}{\partial \Theta}=\frac{D \partial^{2} C}{\partial X^{2}}
$$

where $\Theta=$ time and $D=$ diffusivity of solute in liquid.

Since the constitutional supercooling in the liquid is generally of the order of $0_{1} \cdot{ }^{\circ} \mathrm{C}$. (Rohatgi, unpublished [b]; Rohatgi and Adams, 1965), the concentration gradients in the liquid remain quite small. Since the rate of increase of concentration, $\partial C / \partial \Theta$, is substantially independent of position, Fick's law reduces to an ordinary differential equation:

$$
\frac{d C}{d \Theta}=\frac{D d^{2} C}{d X^{2}} .
$$

Double integration of this equation leads to the difference in concentration between the center and the bounding surface of the interdendritic liquid region:

$$
\Delta C=\frac{a^{2}}{2 D} \frac{d C}{d \Theta}
$$

where $a=$ half thickness of the interdendritic liquid region.

The average solute concentration of liquid $C$ a increases during freezing as follows:

$$
\frac{\bar{C}}{C_{\mathrm{a}}}=\mathrm{I}-f_{\mathrm{s}}
$$

where $\bar{C}=$ initial solute concentration, $f_{\mathrm{s}}=$ fraction solid $=\mathrm{I}-(2 a / L), L=$ center to center distance between adjacent dendrite plates.

Substituting Equation (4) into (3) gives the concentration difference as a function of dendrite spacing, freezing rate, overall concentration and diffusivity:

$$
\Delta C=\frac{L^{2} \bar{C} d f_{\mathrm{s}}}{8 D d \Theta}
$$

The supercooling resulting from this concentration difference is:

$$
\Delta T=m \Delta C=\frac{L^{2} m \bar{C} d f_{\mathrm{s}}}{8 D d \Theta}
$$

where $m=$ slope of the liquidus line on the pertinent phase diagram. 


\section{Freezing Systems and Heat Transport}

\section{Freezing of droplets}

This technique consists of immersing small droplets of aqueous solution into a large quantity of a cold organic liquid (20 per cent kerosene, 80 per cent mineral oil). The organic medium is maintained at a temperature (typically $-20^{\circ} \mathrm{C}$.) substantially below the liquidus temperature of the solution. The relative density and the viscosity of the organic liquid are such that the droplet sinks slowly through it. The droplet remains perfectly spherical during freezing.

The size of the droplet and the ratio of its thermal diffusivity to that of the medium were such that temperature gradients within the droplet during freezing were negligible. Under these conditions the solidification rate did not vary either with position within the droplet or with time. In other words, the solidification rate was uniform with respect to space and time. Droplet diameters are typically of the order of $0 \cdot 2-0 \cdot 3$ in. $(5 \cdot 1-7 \cdot 6 \mathrm{~mm}$.). The principal advantage of uniform freezing conditions is that the resulting dendrite spacings are uniform from the surface to the center of the droplet.

The freezing time of a droplet (French, unpublished) is proportional to the square root of its diameter at any given temperature of the organic coolant.

\section{Unidirectional freezing system}

In this system aqueous solutions are poured into a "Tygon" tube fitted on a copper chill which is kept cool by freezing mixtures. The solution freezes under conditions of unidirectional heat flow from the chill surface. Unidirectional growth of ice from a constant-temperature surface is a heat-transfer situation of practical importance; it is manifested in nature during vertical freezing of saline-water pools with the atmosphere acting as a heat sink. Heat-transfer analysis during unidirectional solidification of solutions is more complicated, since the latent heat is evolved over a range of temperatures. Temperature gradients set up in the liquid are accompanied by the formation of a solid and a solid-plus-liquid zone growing from the chill surface. Freezing in these zones takes place in accordance with temperature patterns fully describable by solutions to Fourier's law of heat conduction:

$$
\frac{\partial T}{\partial \Theta}=\frac{\alpha \partial^{2} T}{\partial y^{2}}
$$

where $T$ is temperature as a function of time, $\Theta$, and distance $y$ from the chill surface. $\alpha$ is the thermal diffusivity.

In the present situation of freezing from a constant-temperature chill surface, the temperature profiles can be represented to as close an approximation as desired by a combination of error-function equations. The temperature isotherms are parallel to the chill surface and they move at a parabolic rate. This is documented by observation of the eutectic temperature isotherm which is readily visible during growth as the limit of the all-solid region.

In view of growth conditions, actual-temperature distribution can be well approximated by a combination of two error-function equations describing the conditions in different temperature regions. For heat-transfer analysis the freezing material is approximated by two zones having different constant specific heats (Fig. 3). The specific heat of the forward zone II (which has a temperature above $T_{\mathrm{s}}$ ) is taken as equal to the effective specific heat of the liquid-solid region just below the liquidus temperature. The specific heat of material in zone I (which has a temperature below $T_{\mathrm{s}}$ ) is taken as equal to that of the solid. The error-function equations describing the temperature profiles (Fig. 4) in each zone are of the following form:

$$
\begin{array}{cc}
T-T_{\mathrm{i}}=A \operatorname{erf} \frac{y}{2\left(\alpha_{\mathrm{I}} \Theta\right)^{\frac{1}{2}}} & \text { Zone I, } \\
T-T_{\mathrm{L}}=B \operatorname{erfc} \frac{y}{2\left(\alpha_{\mathrm{II}} \Theta\right)^{\frac{1}{2}}} & \text { Zone II, }
\end{array}
$$




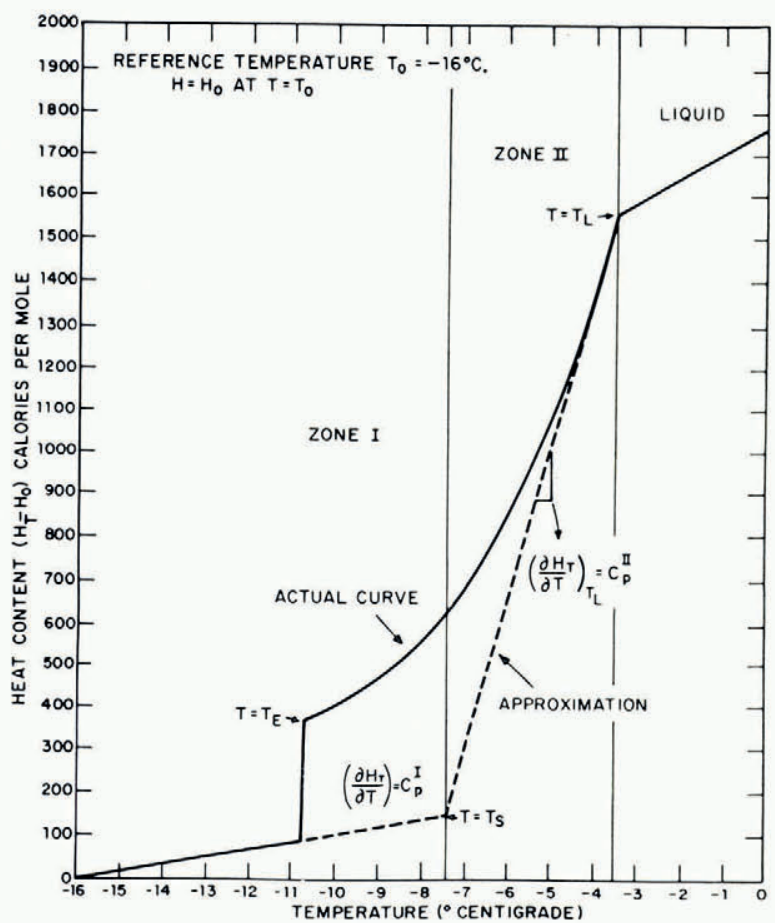

Fig. 3. Variation in heat content of aqueous solutions with temperatures during solidification

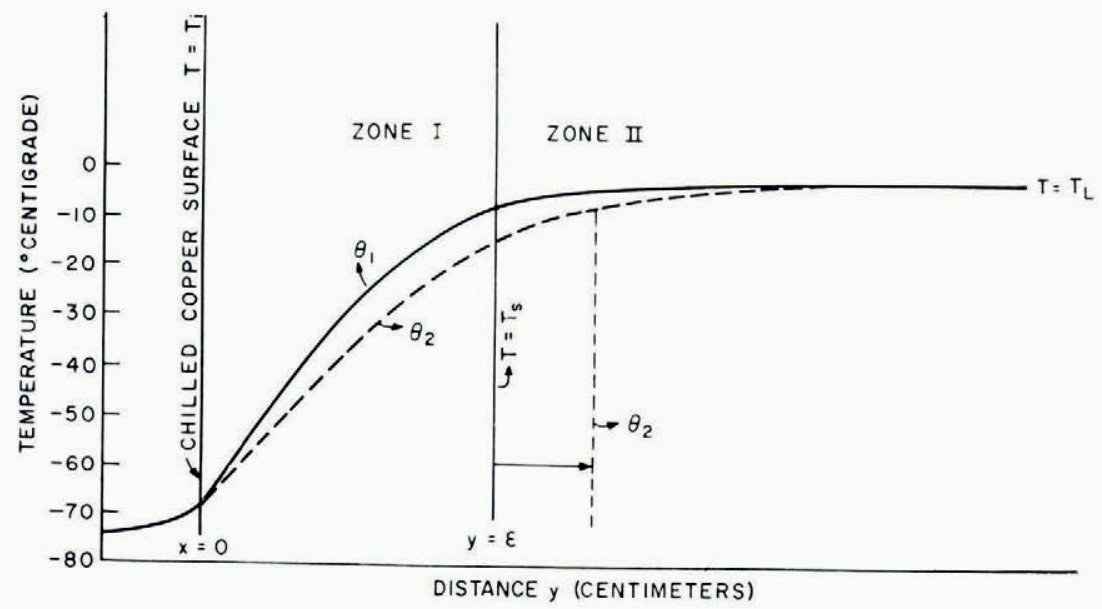

Fig. 4. Schematic representation of temperature profiles when an aqueous solution is brought into contact with a cold chill 
where $\alpha_{\mathrm{I}}, \alpha_{\mathrm{II}}=$ thermal diffusivities in zones $\mathrm{I}$ and II, respectively, and $A, B=$ constants, $T_{\mathrm{i}}=$ chill surface temperature, $T_{\mathrm{L}}=$ liquidus temperature.

The boundary conditions and the approximations used in evaluating the constants are described in detail by Rohatgi and Adams (in press). These temperature distributions can be transformed into a description of freezing events by making use of phase-diagram relationships:

$$
\begin{array}{cc}
\frac{T_{\mathrm{L}}}{\mathrm{I}-f_{\mathrm{s}}}=T_{\mathrm{i}}+A \operatorname{erf} \frac{y}{2\left(\alpha_{\mathrm{I}} \Theta\right)^{\frac{1}{2}}} & \text { Zone I, } \\
\frac{T_{\mathrm{L}}}{\mathrm{I}-f_{\mathrm{s}}}=T_{\mathrm{L}}+B \operatorname{erfc} \frac{y}{2\left(\alpha_{I I} \Theta\right)^{\frac{1}{2}}} & \text { Zone II. }
\end{array}
$$

Freezing rates at different distances from the chill obtained by differentiation of Equations (IO) and (I I) are of the form:

$$
\begin{array}{cc}
\left(\frac{d f_{\mathrm{s}}}{d \Theta}\right)_{y}^{\mathrm{I}}=\frac{A y}{2 T_{\mathrm{L}}\left(\alpha_{\mathrm{I}}\right)^{\frac{1}{2}}} \cdot \frac{\left(\mathrm{I}-f_{\mathrm{s}}\right)^{2}}{\Theta^{3 / 2}} \cdot \frac{2}{\pi^{\frac{1}{2}}} \cdot \exp \left[-\left\{\frac{y}{2\left(\alpha_{\mathrm{I}} \Theta\right)^{\frac{1}{2}}}\right\}^{2}\right] & \text { Zone I, } \\
\left(\frac{d f_{\mathrm{s}}}{d \Theta}\right)_{y}^{\mathrm{II}}=-\frac{B y}{2 T_{\mathrm{L}}\left(\alpha_{\mathrm{II}}\right)^{\frac{1}{2}}} \cdot \frac{\left(\mathrm{I}-f_{\mathrm{s}}\right)}{\Theta^{3 / 2}} \cdot \frac{2}{\pi^{\frac{1}{2}}} \cdot \exp \left[-\left\{\frac{y}{2\left(\alpha_{\mathrm{II}} \Theta\right)^{\frac{1}{2}}}\right\}^{2}\right] & \text { Zone II. }
\end{array}
$$

Figure 5 shows the freezing-rate distribution (Rohatgi and Adams, in press) during unidirectional solidification of a $\mathrm{I} \cdot \mathrm{oN}$ potassium chloride ingot. The results of heat-flow analysis can be summarized as:

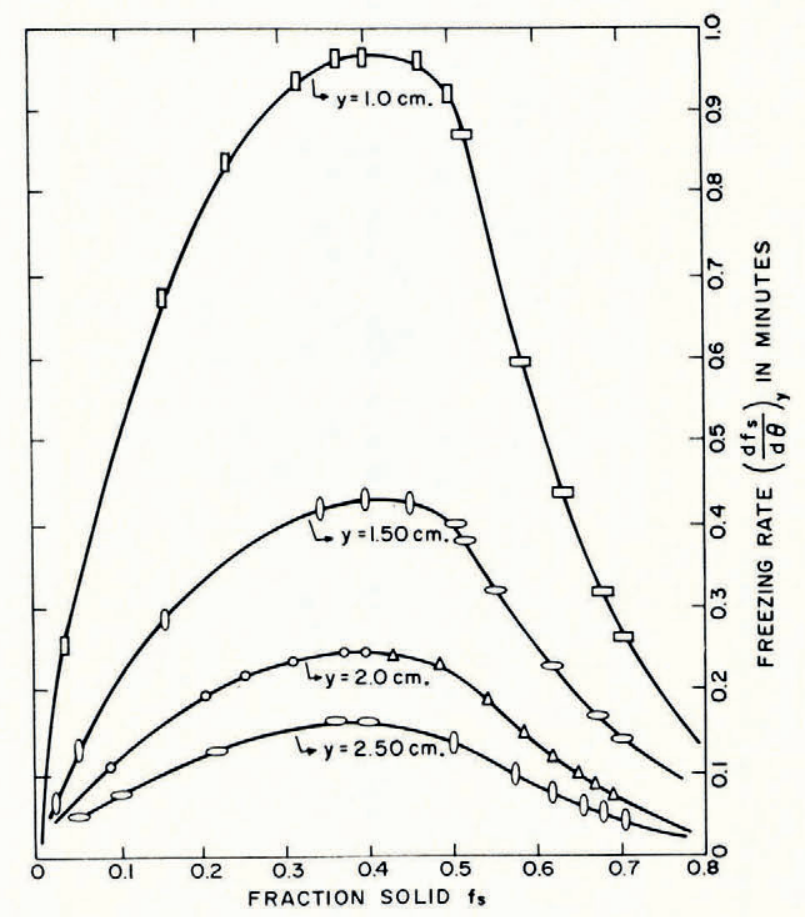

Fig. 5. Freezing rates of $I \cdot O \mathcal{N}$ potassium chloride solution versus fraction solid at different distances from a surface at $-70^{\circ} \mathrm{C}$. in contact with the solution

i. When an aqueous solution at its liquidus temperature is presented to a constanttemperature chill surface, the liquid at each level is subjected to a spectrum of freezing rates. The freezing rate at each level starts low, goes through a maximum and then decreases during the freezing cycle. 
ii. The spectrum of freezing rates is different at different distances from the chill and the maximum freezing rate, as well as the average freezing, is inversely proportional to the square of the distance from the chill:

$$
\begin{aligned}
& \left(\frac{d f_{\mathrm{s}}}{d \Theta}\right)^{\mathrm{M}} \propto \frac{\mathrm{I}}{y^{2}} \\
& \left(\frac{d f_{\mathrm{s}}}{d \Theta}\right)^{\wedge} \propto \frac{\mathrm{I}}{y^{2}}
\end{aligned}
$$

where $y=$ distance from chill. Superscripts $\mathrm{M}$ and $\mathrm{A}$ mean maximum and average, respectively.

\section{Freezing rate and freezing time}

The freezing rate is expressed as the rate of fraction solid with time and has the dimensions of reciprocal time. Expressed in this way, the freezing rate has been found determinative of dendrite spacing. In some cases, such as the freezing of droplets in a cold organic liquid, the freezing rate is substantially uniform from beginning to end of solidification. In this special case the freezing time is numerically identical to the inverse freezing rate.

\section{Specimen Preparation and Migrography}

Thin slices are cut from droplets of unidirectionally frozen samples and mounted on a transparent glass slide by freezing small drops of water around their periphery. They are then polished on a series of emery papers; the final polishing is done on a soft tissue paper. A Leitz biological microscope was used for structural observations; photography was done by mounting a $35 \mathrm{~mm}$. Exacta camera on the eyepiece tube using light transmitted through the specimen. Specimen preparation and photography were done at $-40^{\circ} \mathrm{C}$.

\section{Results And Discussion}

\section{Dendritic structure}

The solid aggregate formed on freezing of aqueous solutions consists of groups of parallel plates of ice. Examination under polarized light shows the orientation of plates within a group is the same; different groups have different orientations. Figure 6 shows schematically the structural features of a group of dendrites after complete solidification. Figure 8 shows a microphotograph of a typical aggregate sectioned perpendicular to direction of growth. The dark phase between the ice plates is salt-ice eutectic, the very last material to solidify.

\section{Effect of freezing rate}

Dendrite-spacing measurements were made on different size droplets for four different solutions (Fig. 7). The freezing time of a droplet is proportional to its diameter. This means that dendrite spacing is directly proportional to the square root of freezing time, or, stated another way, proportional to the inverse square root of freezing rate (Fig. 7).

In unidirectional samples frozen from a constant-temperature chill surface the dendrite spacing increases linearly with distance from the chill surface. Figures 8 and 9 show transverse sections of a sample at increasing distances from the chill; the sample was made from a $\mathrm{I} \cdot \mathrm{oN}$ potassium chloride solution in contact with a chill at $-70^{\circ} \mathrm{C}$. Examination of such successive sections and some longitudinal sections has indicated quite conclusively that the dendrite spacing increases principally by divergent growth of neighboring plates. The divergence of plates is accommodated by the decrease in the number of groups per unit area, with increasing distance from the chill. Out of the large number of groups that are produced next to the chill by very rapid initial freezing, only a few survive at larger distances from the chill. 

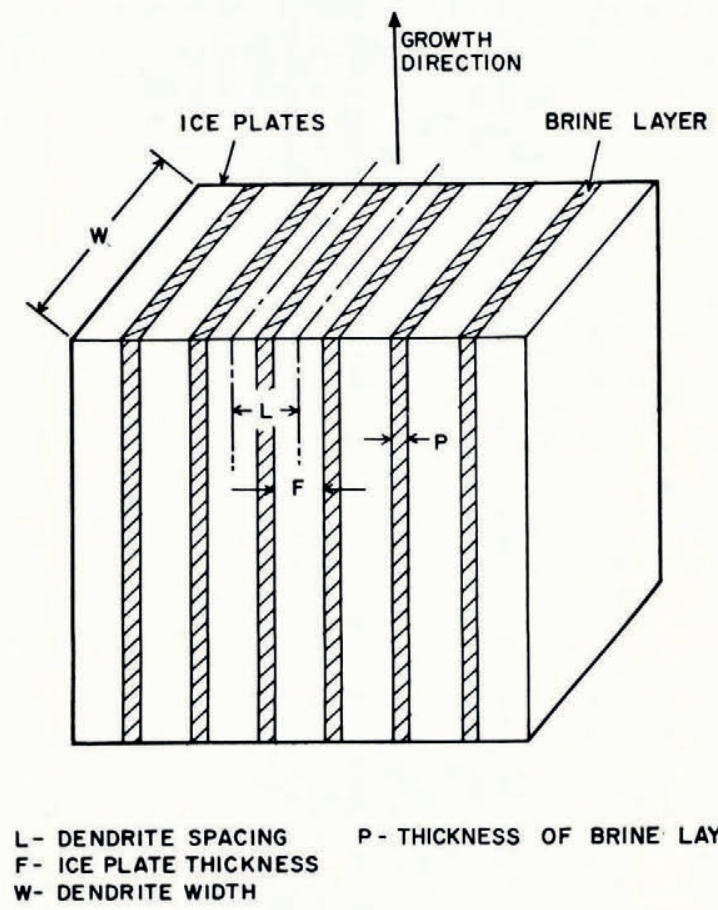

Fig. 6. Characteristic parameters of a group of dendrites of ice with solute entrapped in between

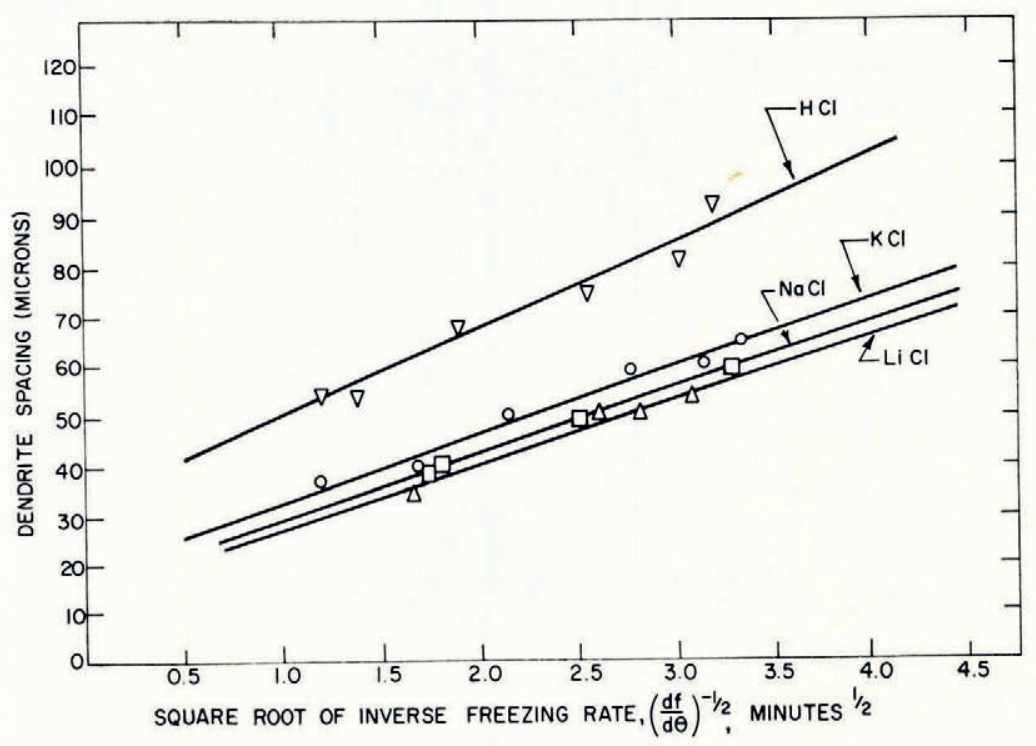

Fig. 7. Dendrite spacing as a function of the square root of the inverse freezing rate in droplets of four different solutions at a concentration level of $0 \cdot 4$ mole $/$ l. 
In both single- and mixed-solute systems studied so far, dendrite spacing has been found to increase linearly with the distance from the chill (Fig. Io). Each position in the sample during growth from a constant-temperature chill is subjected to a spectrum of freezing rates (Fig. 5). The maximum freezing rate at any level is proportional to the square of its distance from the chill. The dendrite spacing is, therefore, inversely proportional to the square root of the maximum freezing rate (Fig. I I).

The dendrite spacings in the two systems were equal when the maximum freezing rate in the unidirectional freezing system equals the constant freezing rate of the droplet system.

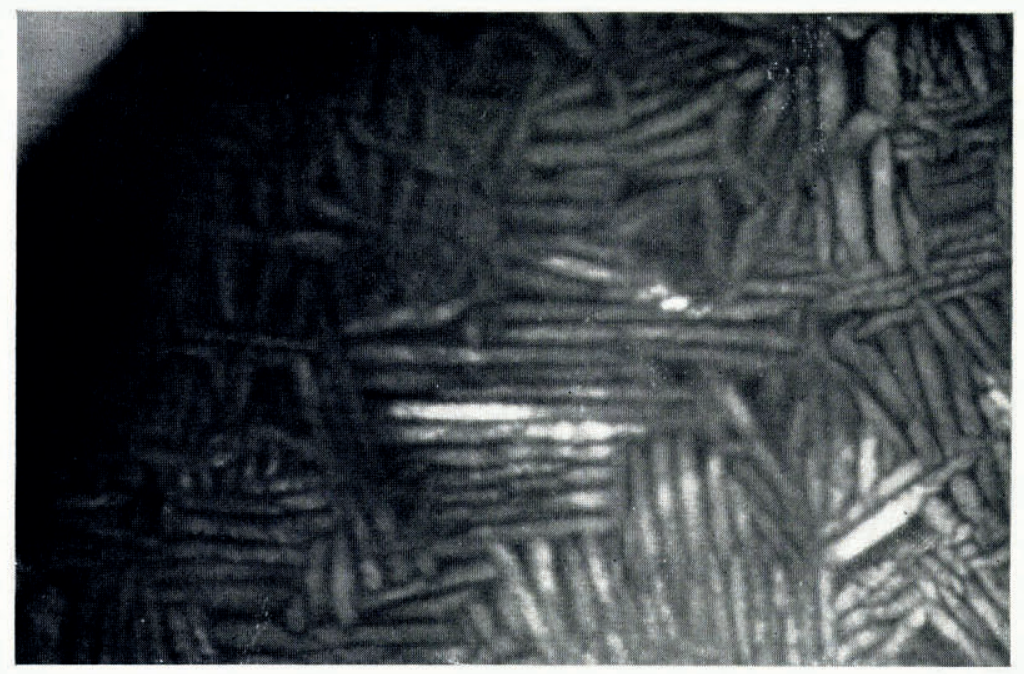

Fig. 8. Transverse section of a unidirectional sample from a potassium chloride solution, $0.9 \circ \mathrm{cm}$. from $a-70^{\circ} \mathrm{C}$. chill surface, $\times 23$

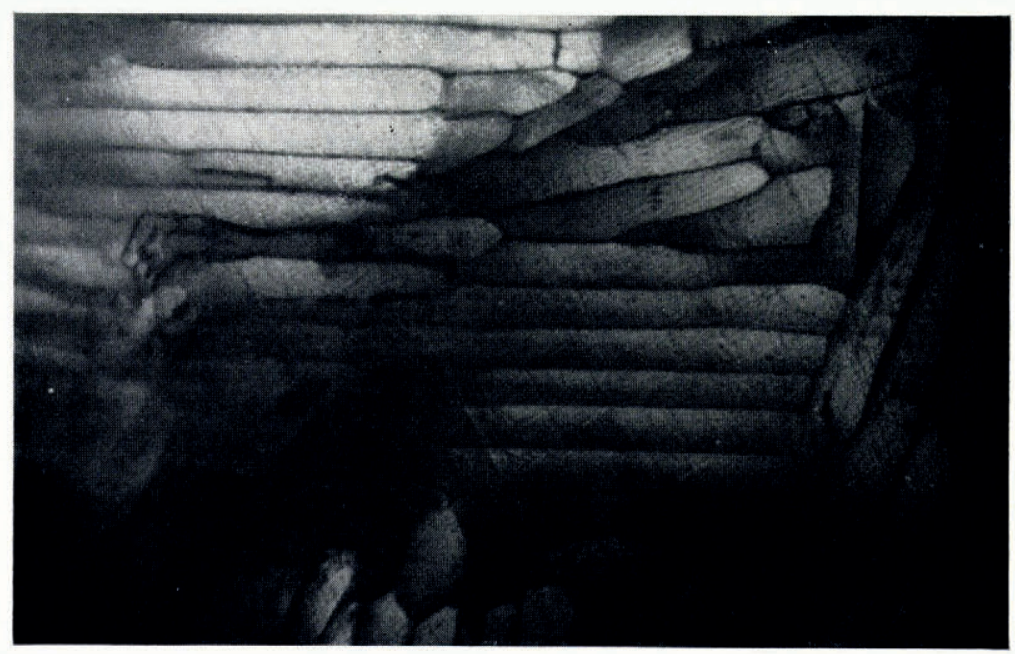

Fig. 9. The same sample as in Figure $8,3 \cdot 2 \mathrm{~cm}$. from the chilled surface, $\times 23$ 
In summary, the relationship between dendrite spacing and freezing rate, $d f_{\mathrm{s}} / d \Theta$, can be expressed:

$$
L=K_{\mathrm{I}}\left(\frac{d f_{\mathrm{s}}}{d \Theta}\right)^{-\frac{1}{2}}+K_{\mathrm{r}}^{\prime}
$$

where $K_{\mathrm{I}}$ and $K_{\mathrm{I}}^{\prime}$ are constants.

This means (Equations (5) and (6)) that the interdendritic supercooling, $\Delta \mathcal{T}$, or supersaturation, $\Delta C$, does not vary with freezing rate (i.e. with position in the unidirectional specimen).

\section{Effect of solute diffusivity}

Dendrite spacings have been measured for solutions of potassium chloride, sodium chloride and lithium chloride at the same concentration and freezing rate. Figure I 2 shows a linear increase of dendrite spacing with solute diffusivity for the droplet freezing systems. Figure 13 shows similar results for the unidirectional freezing system; the dendrite spacing at a fixed distance from the chill surface increases linearly with solute diffusivity. The dendrite spacing can be expressed as a function of solute diffusivity in the form:

$$
L=K_{2} D+K_{2}^{\prime}
$$

where $D$ is the diffusivity of the solute and $K_{2}$ and $K_{2}{ }^{\prime}$ are constants.

The supersaturation $\Delta C$ and supercooling $\Delta T$ in the interdendritic liquid increase in the following manner:

$$
\Delta C=\frac{\Delta T}{m}=\frac{\bar{C}\left(K_{2} D+K_{2}^{\prime}\right)^{2} d f_{\mathrm{s}}}{8 D d \Theta} \text {. }
$$

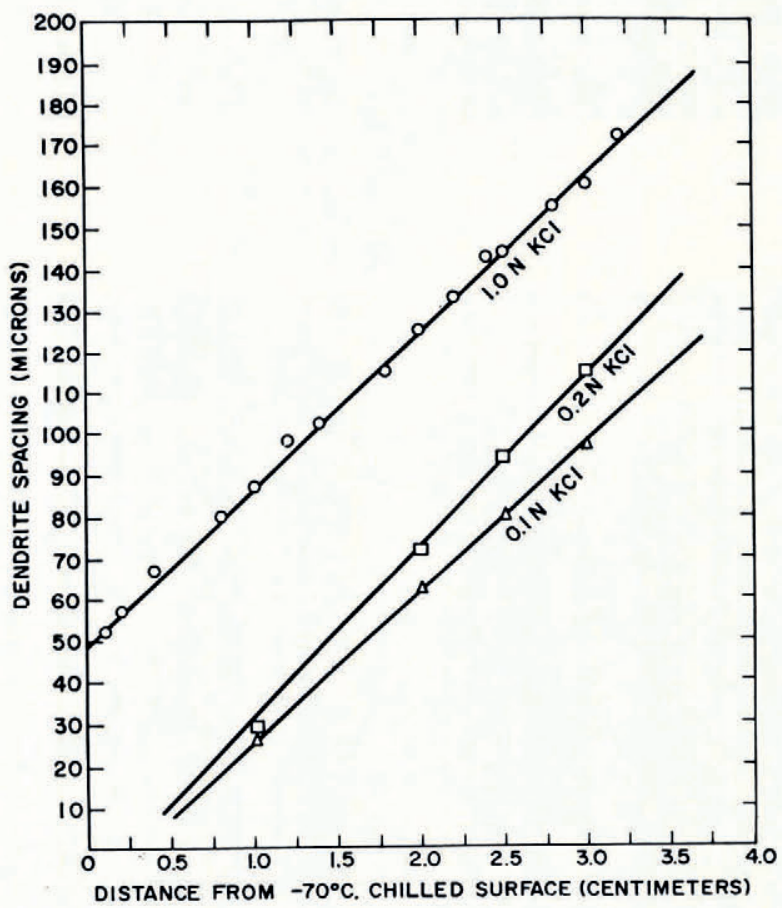

Fig. 1o. Variation of dendrite spacing with distance in unidirectional samples of potassium chloride solutions at different concentration levels 


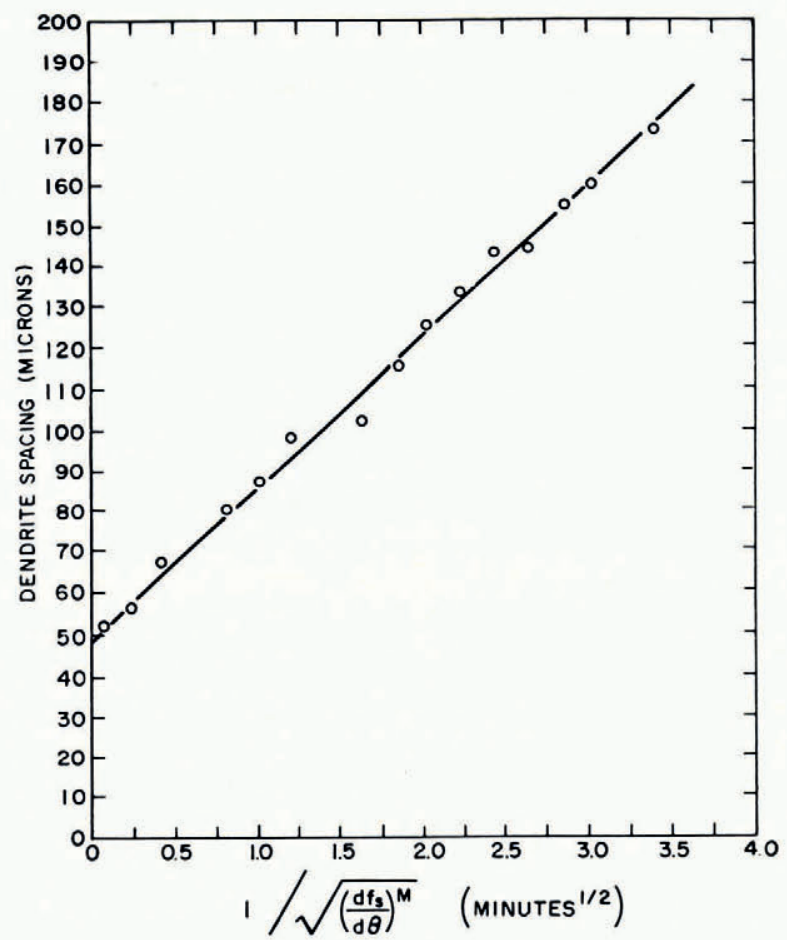

Fig. II. Dendrite spacing in $I \cdot O \mathcal{N}$ potassium chloride ingot as a function of the reciprocal of the square root of the maximum freezing rate at different distances from the chill surface at $-70^{\circ} \mathrm{C}$.

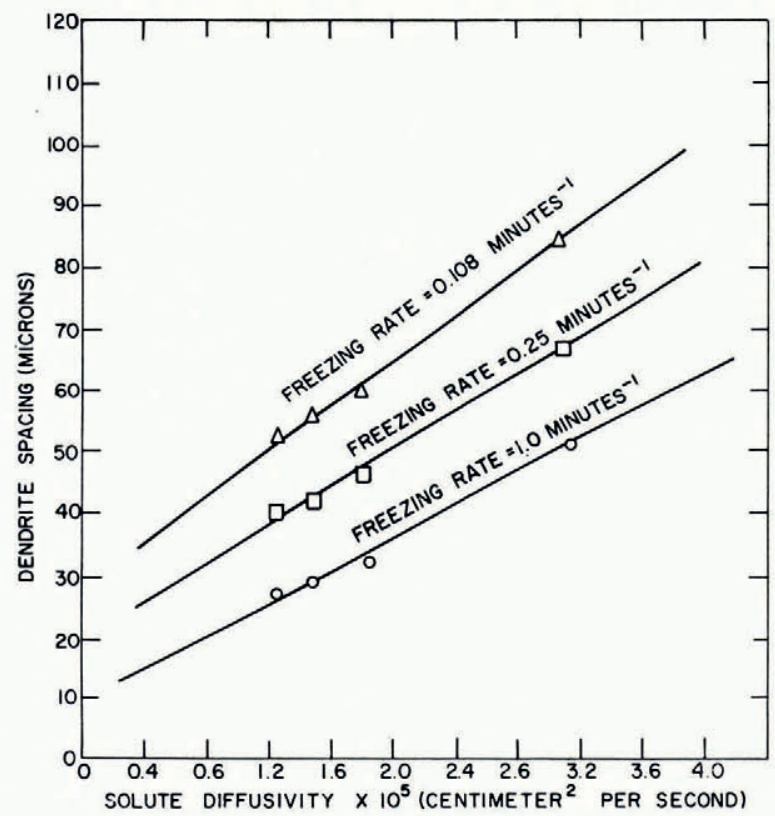

Fig. I2. Variation of dendrite spacing with solute diffusivity in droplets containing $0 \cdot 4$ mole/l. of solute 
For a system such as freezing of droplets, the transverse growth velocity, $V$, of the solidliquid interface is given by:

$$
V=\frac{L}{2 \Theta_{f}}=\frac{L d f_{\mathrm{s}}}{2 d \Theta}=\frac{\left(K_{2} D+K_{2}{ }^{\prime}\right) d f_{\mathrm{s}}}{2 d \Theta} .
$$

At a given freezing rate the transverse growth velocity is higher the higher is the solute diffusivity.

\section{Effect of solute concentration and magnetic fields}

Dendrite spacing obtained on freezing aqueous solutions increases linearly with solute concentration. Figure I4 shows this for sodium chloride solutions. Similar effects have been observed in unidirectional samples frozen from potassium chloride (Fig. Io), sodium chloride and lithium chloride solutions. Solute concentration has been found to have a similar effect on dendrite spacings obtained on freezing of metallic solutions (Rohatgi, unpublished [a]).

The relationship between dendrite spacing, $L$, and solute concentration, $\bar{C}$, under identical freezing conditions is of the form:

where $K_{3}$ and $K_{3}^{\prime}$ are constants.

$$
L=K_{3} \bar{C}+K_{3}{ }^{\prime}
$$

The observed increase of dendrite spacing with solute concentration means that (Equations (5) and (6)) supersaturation $\Delta C$ and supercooling $\Delta T$ in interdendritic liquid increase with solute concentration in the following manner:

$$
\Delta C=\frac{\Delta T}{m}=\frac{\bar{C}\left(K_{3} \bar{C}+K_{3}{ }^{\prime}\right)^{2} d f_{\mathrm{s}}}{8 D d \Theta} .
$$

The transverse growth velocity, $V$, of dendrite surfaces increases with solute concentration.

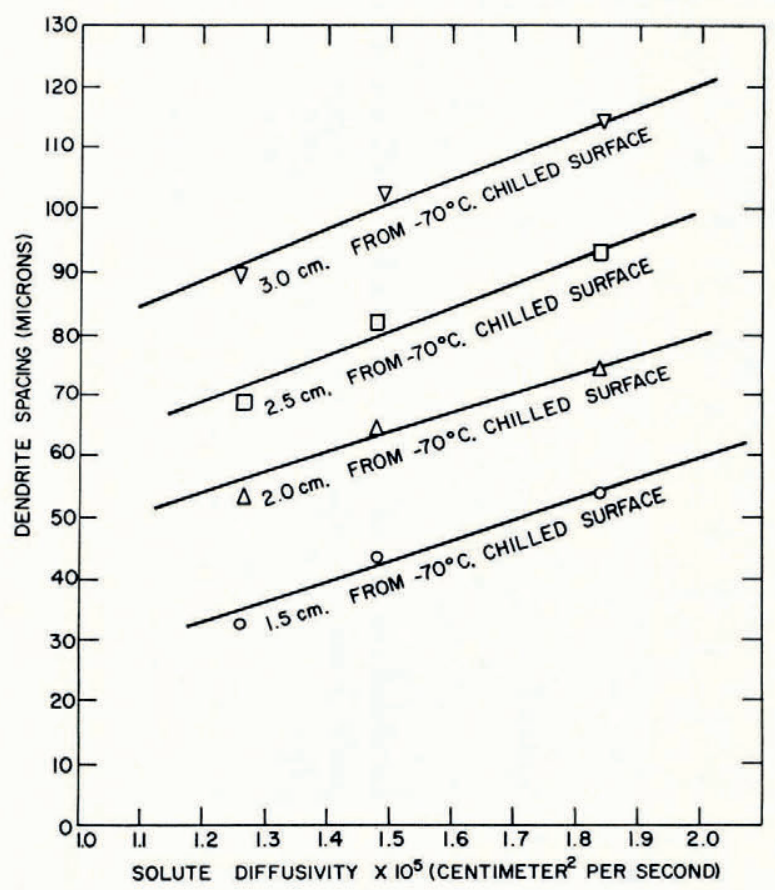

Fig. 13. Variation of dendrite spacing with solute diffusivity in unidirectional samples containing 0.2 mole/l. of solute 


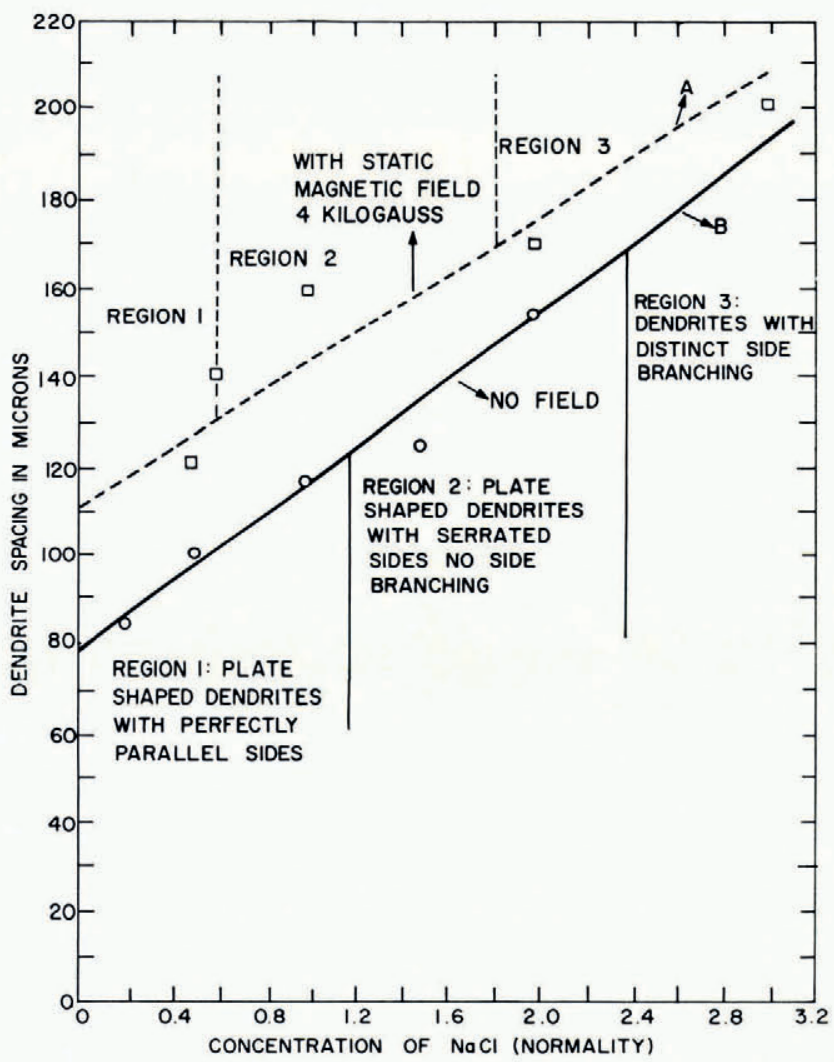

Fig. I4. Variation of dendrite spacing and dendrite morphology with solute concentration in sodium chloride droplets

At a fixed freezing rate an increase in solute concentration above a critical value leads to development of side branches on ice platelets (Rohatgi and Adams, 1965). Curve B in Figure I 4 shows that up to sodium chloride concentrations of $1 \cdot 2 \mathrm{~N}$, and at a freezing rate of $0 \cdot 006$ sec. ${ }^{-1}$, the ice plates have perfectly smooth sides (Fig. 15) but at higher solute concentrations the plates develop serrations and distinct side branches (Fig. I6).

The effect of a magnetic field at different solute concentrations is demonstrated by comparison of curves A and B in Figure I4. In all respects, imposition of a magnetic field is equivalent to increasing sodium chloride concentration; it increases the dendrite spacing and promotes the development of side branches on ice plates.

Structures from mixed solutions

Freezing of multi-component solutions involves the simultaneous rejection of more than one solute species at the solid-liquid interface. These solutions more closely simulate natural saline waters which generally contain several solutes. Solutions containing more than one solute (Rohatgi and Adams, I965; Brush, unpublished) freeze dendritically in the same manner as single-solute solutions.

Studies with solutions from the family $\mathrm{NaCl}-\mathrm{KCl}-\mathrm{LiCl}-\mathrm{H}_{2} \mathrm{O}$ suggest the following trends in dendritic structure:

i. If two solutes are present in equal amounts, the dendrite spacing lies between the values obtained with individual solutions in which each solute is present at its same concentration (Fig. I7). 
ii. The solute present in large concentrations tends to govern the dendrite spacing; small additions of other solutes cause a relatively small shift in the dendrite spacing. If the secondary solute has a higher diffusivity than the principal solute, dendrite spacing is increased and vice versa. Figure $\mathrm{r} 8$ shows small additions of a faster-moving potassium chloride cause an increase in the dendrite spacing obtained in a sodium chloride solution, whereas additions of a slower-moving lithium chloride decrease dendrite spacing.

iii. In solutions containing the constituent solutes in a fixed ratio, spacing is larger the greater is the total solute concentration (Fig. I9).

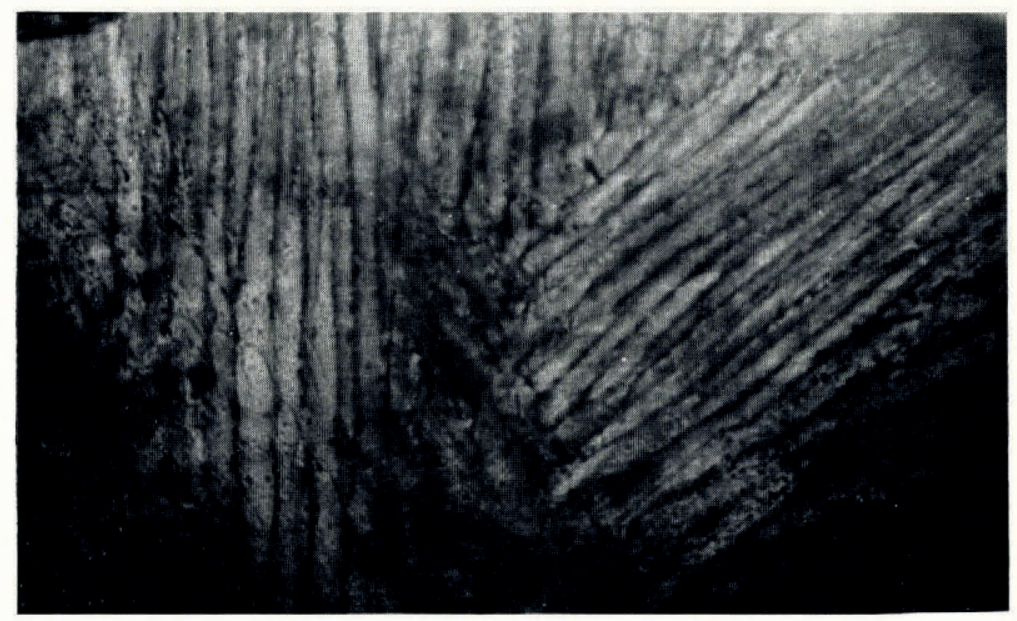

Fig. ${ }_{15} \cdot 0 \cdot 2 \mathcal{N}$ sodium chloride solution droplet. Freezing rate $0 \cdot 3^{6} \mathrm{~min}^{-1}, \times 23$

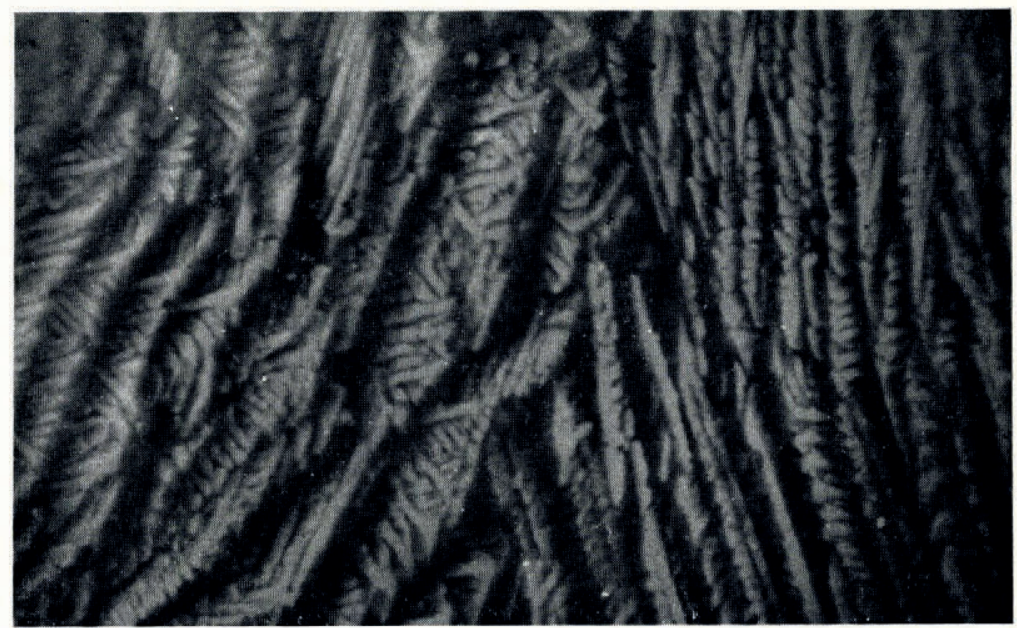

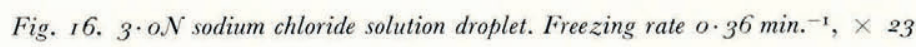



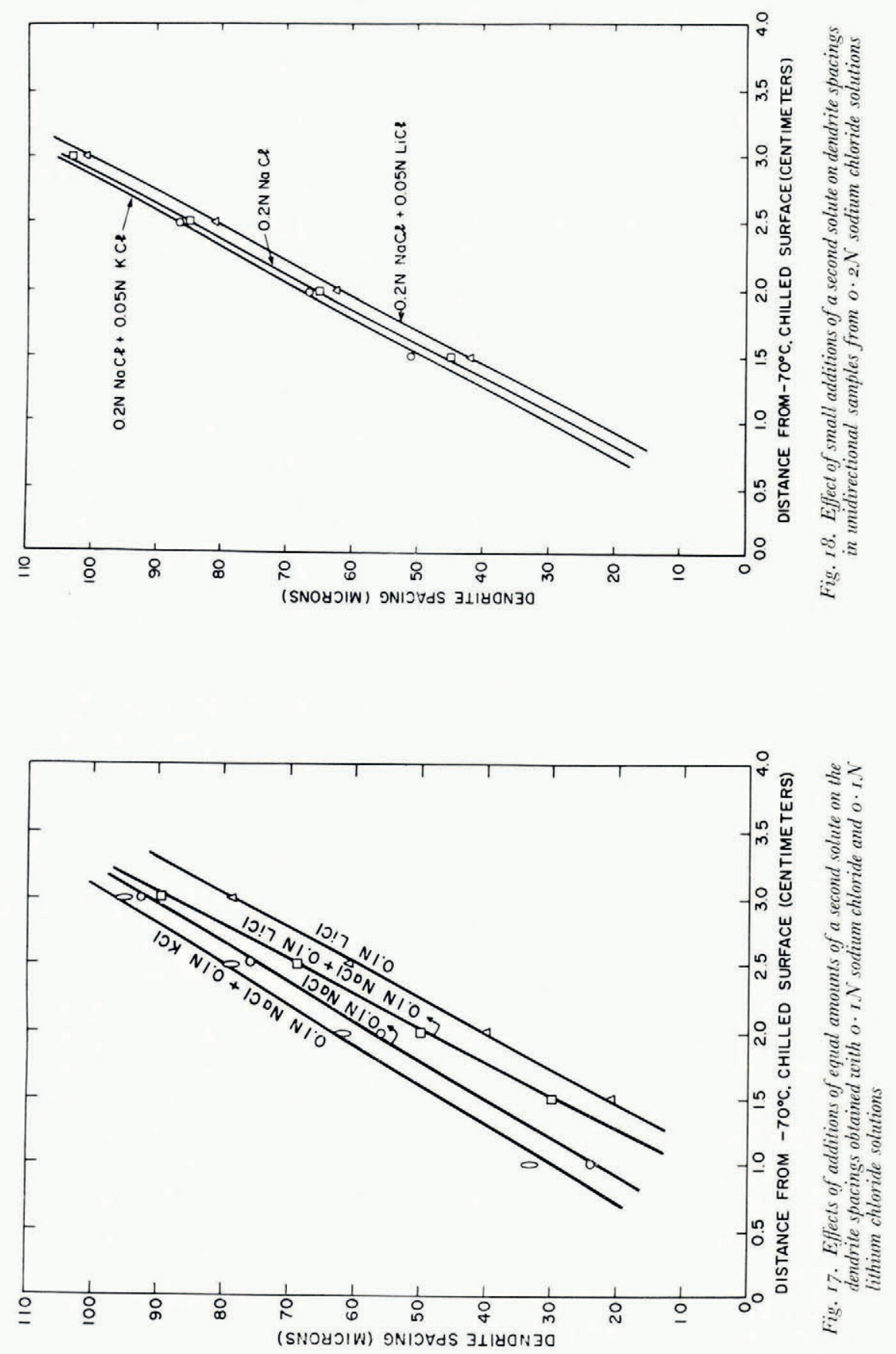


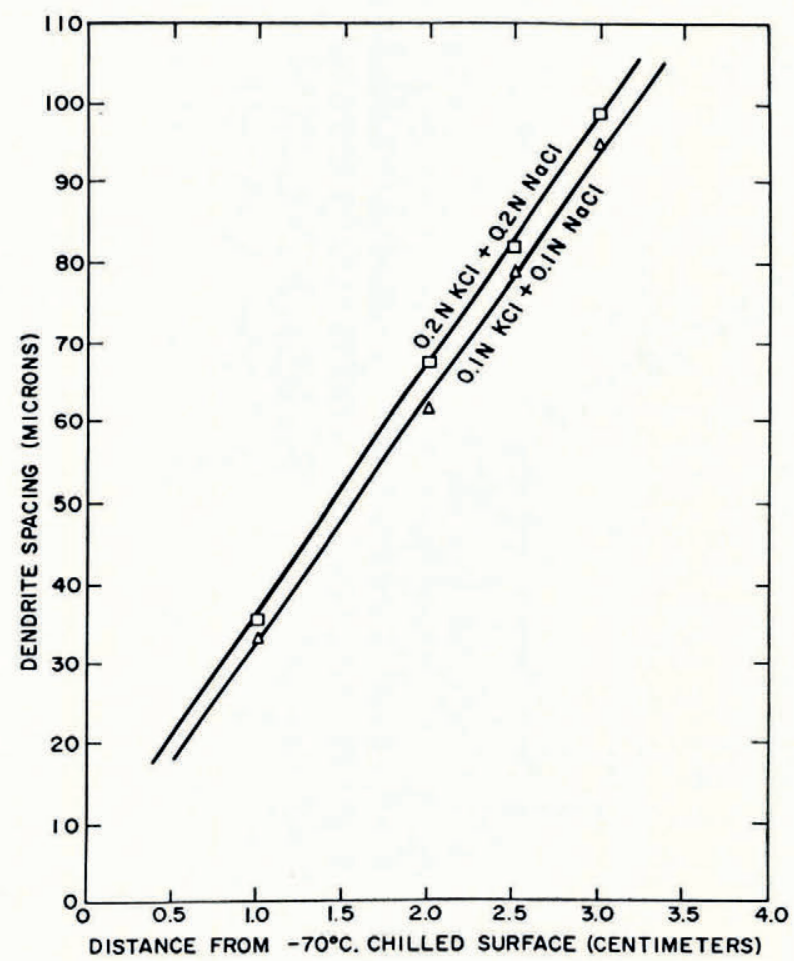

Fig. Ig. Increase in dendrite spacing with total solute concentration in ternary solutions containing equal amounts of potassium chloride and sodium chloride

\section{Conclusions}

I. Binary, ternary and quaternary aqueous solutions freeze as groups of parallel plateshaped dendrites of pure ice separated by layers of brine.

2. In systems where the freezing rate remains constant over the entire solidification cycle, the dendrite spacing is proportional to the square root of the freezing time.

3. In unidirectional growth from a constant-temperature chill, the solution at each location is subjected to a spectrum of freezing rates. The freezing rate starts low, goes through a maximum and then decreases to the end of solidification. The dendrite spacing increases linearly with distance from the chill surface; at each location dendrite spacing is inversely proportional to the square root of the maximum freezing rate.

4. Interdendritic supersaturation, $\Delta C$, or supercooling, $\Delta T$, are independent of freezing rate

5. An increase in solute concentration causes an increase in the dendrite spacing and, at relatively high concentrations, side branching of primary dendrites takes place.

6. In binary solutions dendrite spacing increases linearly with solute diffusivity at fixed values of concentration and freezing rate.

7. When more than one solute is present in solution, dendrite spacing is governed by the concentration and the diffusivity of each of the solutes.

8. Application of external magnetic fields causes an increase in dendrite spacing and promotes the development of side branches on ice plates.

MS. received 25 November 1966 


\section{REFERENCES}

Bennington, K. O. 1963 . Some chemical composition studies on Arctic sea ice. (In Kingery, W. D., ed. Ice and snow, properties, processes, and applications: proceedings of a conference held at the Massachusetts Institute of Technology, February 12-16, 1962. Cambridge, Mass., The M.I.T. Press, p. 248-57.)

Brush, E., jr. Unpublished. Dendritic solidification of aqueous solutions containing mixtures of three solutes. [S.M. thesis, M.I.T., I965.]

Dorsey, N. E. ${ }^{1} 948$. The freezing of supercooled water. Transactions of the American Philosophical Society, New Series, Vol. 38, Pt. 3, p. 247-328.

French, D. N. Unpublished. Solidification of aqueous solutions. [Sc.D. thesis, M.I.T., 1962.]

Harrison, J. D., and Tiller, W. A. 1963 . Controlled freezing of water. (In Kingery, W. D., ed. Ice and snow; properties, processes, and applications: proceedings of a conference held at the Massachusetts Institute of Technology, February I2-I6, 1962. Cambridge, Mass., The M.I.T. Press, p. 2 I $5^{-25}$.)

Himes, R. C., and others. 1959. Zone freezing in demineralizing saline waters, by R. C. Himes, S. E. Miller, W. H. Mink and H. L. Goering. Industrial and Engineering Chemistry, Vol. 51, No. I I, p. I345-48.

Kingery, W. D. 1960. Applied glaciology - the utilization of ice and snow in Arctic operations. Fournal of Glaciology, Vol. 3 , No. 27 , p. $577-88$.

Rohatgi, P. K. Unpublished [a]. Solidification of eutectic and near eutectic aluminium-copper alloys. [S.M. thesis, M.I.T., 1963.]

Rohatgi, P. K. Unpublished [b]. Dendritic solidification of aqueous solutions. [Sc.D. thesis, M.I.T., I964.]

Rohatgi, P. K., and Adams, C. M., jr. 1965 . Solidification and separation of ice from saline water. U.S. Department of the Interior. Office of Saline Water. Progress Report No. 142.

Rohatgi, P. K., and Adams, C. M., jr. In press. Freezing rate distribution during unidirectional solidification of solutions. Transactions of the Metallurgical Society of AIME (American Institute of Mining, Metallurgical and Petroleum Engineers).

Tiller, W. A., and others. I953. The redistribution of solute atoms during the solidification of metals, by W. A. Tiller, K. A. Jackson, J. W. Rutter and B. Chalmers. Acta Metallurgica, Vol. 1, No. 4, p. 428-37.

Weeks, W. F., and Assur, A. ${ }_{1963}$. Structural control of the vertical variation of the strength of sea and salt ice. (In Kingery, W. D., ed. Ice and snow; properties, processes, and applications: proceedings of a conference held at the Massachusetts Institute of Technology, February $12-16,1962$. Cambridge, Mass., The M.I.T. Press, p. 258-76.) 